\title{
A STUDY ON EXTENDING TECHNOLOGIES LIFESPAN FOR THE ENVIRONMENT SAFETY
}

\begin{abstract}
In recent decades, the technological devices have become a big burden for the environment. In fact, the production processes are depleting the natural resources and the end-of-life processes are emitting big amounts of heavy pollutants and toxic gases. Today, there is an agreement among researchers that the environmental issues must be considered from a life cycle perspective. In order to reduce the negative impacts of technologies on the environment, the best scenario would be to extend their lifespan. However, an old device, is usually linked to low performances, low profit for the manufacturer, additional reparation costs, high risks, etc. In this paper, the DoubleEco (DE) model, an evaluation platform of the compromise between the performances, cost, ecology, safety and lifespan is developed. Also, the environmental impacts of the lifespan are highlighted through the example of personal computers (PCs) and the DE model is applied to three types of grease lubrication as case of study. The results show that (1) evaluating a technology with all its aspects is efficient when deciding whether to extend its lifespan (2) based on the DE model, the lubrication with the longest lifespan has a better evaluation than the two other studied cases.
\end{abstract}

\section{INTRODUCTION}

Until the middle of the 20th century, products were designed to last as long as possible. Since then, shortening the lifespan of products has become "commonplace", motivated by the need to reduce costs, the attractiveness and the convenience of disposability [1]. In addition, the users of modern technologies present an excessive usage behaviour; always looking for better performances and rapidly replacing their devices even when they are still functional. All this, made the quantities of waste and the number of produced units grow at high rates and become thus a big burden for the environment. In fact, the production processes are becoming more and more complex and that is depleting the natural resources and emitting big amounts of toxic gases. Also, the end-of-life processes, such as landfill and recycling, result in the emission of heavy pollutants for the environment. The reason why, many

\footnotetext{
${ }^{1}$ Department of Mechanical Engineering, Nagaoka University of Technology, Japan

*E-mail: amalaabidi93@gmail.com https://doi.org/10.36897/jme/132577
} 
developed countries today, ship their electronic waste (e-waste) to the developing countries as donations or through illegal export. In those countries, e-waste is managed through inappropriate alternatives such as open burning and backyard recycling [2]. Extending the technologies' lifespan would be an efficient solution to help deal with those issues by reducing both the production growth rate and e-waste quantities. However, this approach may be challenging for both users and manufacturers. In this paper, the main challenges of extending the lifespan of a technology are discussed through the example of PCs. Then, the DE model introduced in a previous study [3] is upgraded and applied to a grease lubrication case of study.

\section{PERSONAL COMPUTERS LIFESPAN}

The life cycle of a PC may have different scenarios. Through its life, a PC can have more than one user, it can go through a refurbish and recycling company, be sold at a second-hand shop or in an internet auction or simply be given to another user (Fig. 1).

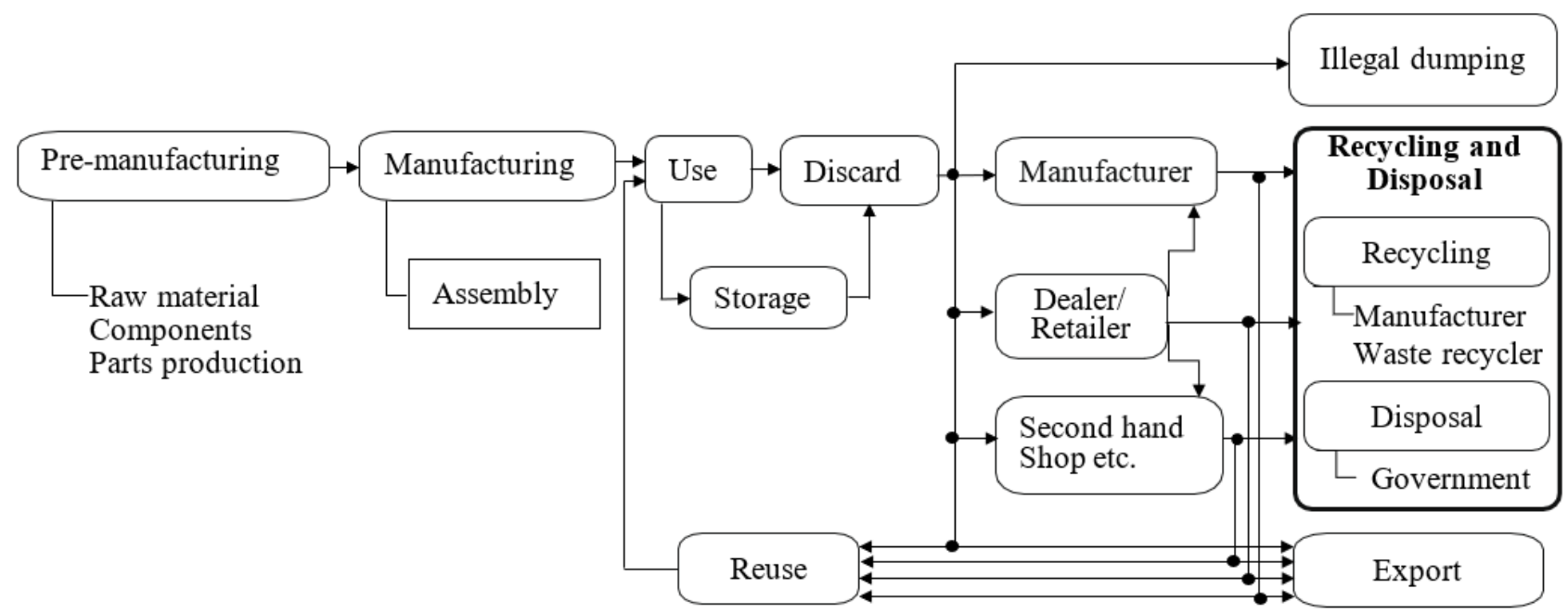

Fig. 1. PCs Life cycle's diagram

The estimation of a PC's lifespan is complicated because it depends on many interconnected parameters (Fig. 2). Also, the number of years between the purchase and the disposal can be different from the period it was actually used. A survey made in 2004 showed that the Japanese residential computer users purchase a new computer every 2.9 years and that the old computer spends 2.8 years in storage before the disposition [4]. This phenomenon reduces the chances of being used by another person as « a PC that is more than 6 years old generally does not have a resale value» [5]. The dynamism of PCs lifespan influences the management strategies and policies dealing with waste like for example, the decisions such as when it is appropriate to landfill the waste or extend its lifespan.

An intensive energy consumption during the manufacturing stage and the users unconscious behaviour combined with a short lifespan made the PCs a big burden for 
the environment. The solution would be to maximize their reuse via reselling or upgrading in order to produce less units and reduce the generated waste. However, the PC market is faced by economic obstacles in addition to difficulties associated with transferring licenses for preinstalled software to secondary owners and lack of a proper blue-book of used computer prices [6]. Besides, the security of personal data pushes the PC manufacturers to make their products difficult to disassemble shortening thus their lifespan. Apple's products for instance, are the best when it comes to data security, but their lifespan is the shortest in the market [7].

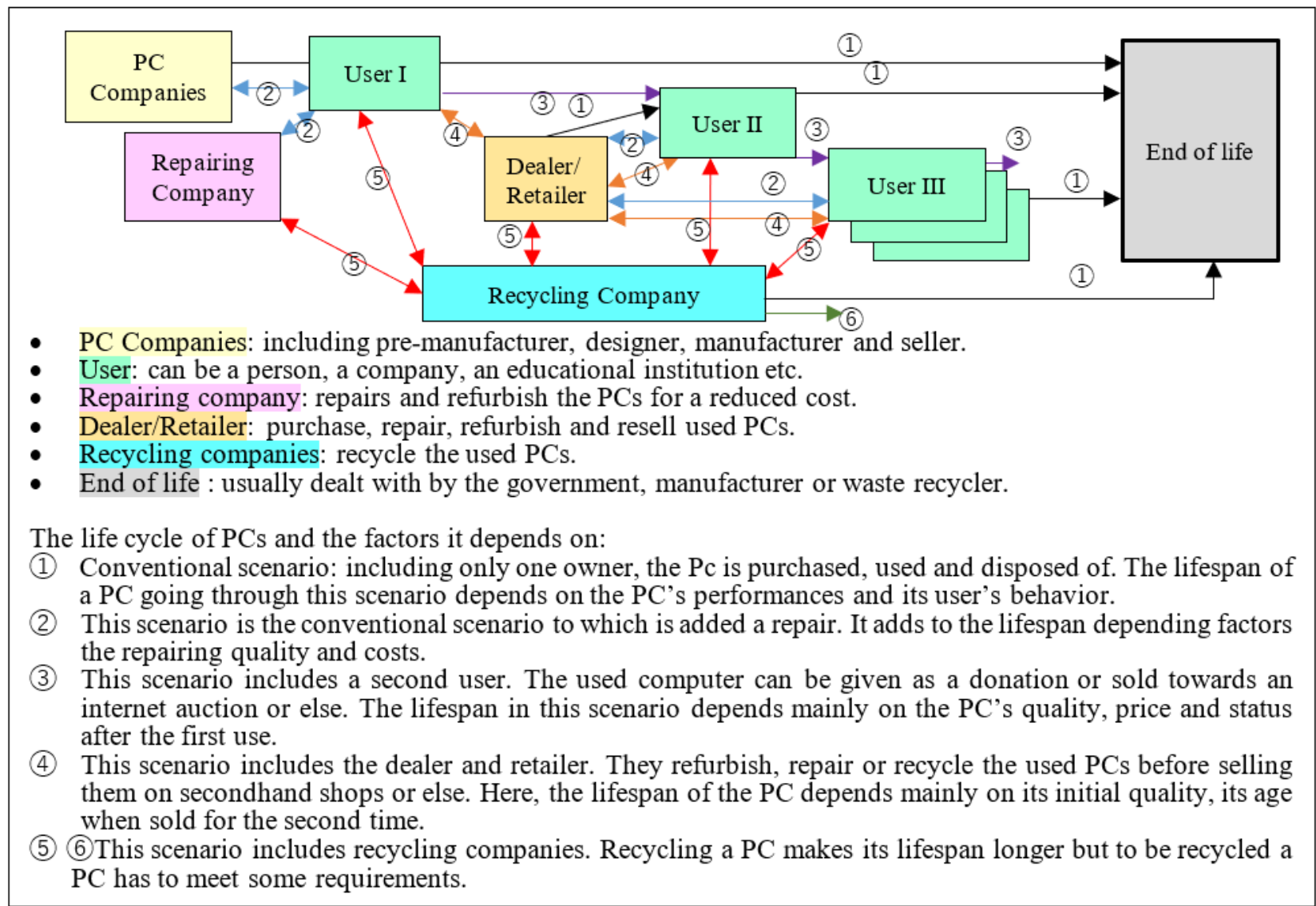

Fig. 2. PCs Life cycle's scenarios

\section{EXTENSION OF THE DOUBLE-ECO MODEL}

Since its inception, the industry has continuously been evolving. When it first appeared, only the performances mattered. Then, at the end of the 20th century, when industrial products became widespread and the competition between manufacturers increased, minimizing the cost became essential to survive the competition and attract customers. A while after that, realizing the impact of industrial products on the environment, an importance started to be given to this issue. Then, the risks management became common in several fields and more recently, the lifespan of technologies has been added to the list of parameters to be taken into 
account. When designing a system, upgrading it or changing its settings, the impact of the selected settings or the change to make should be evaluated not only on certain parameters but, on the system as a whole. For instance, reducing the costs of a device by integrating low cost components, may be estimated as efficient when only the cost and performances in the short-term are evaluated but, in the other hand, this may lower the long-term performances, increase the risk of being damaged and reduce the lifespan. In this context, the DE model was developed as an evaluation platform for the performances, costs, environmental impacts for a given technology.

$$
\text { DE Index }(\%)=\frac{\text { Real implementation }}{\text { Ideal implementation }}
$$

The DE Index (1) consists on a dimensionless index that combines all the mentioned evaluations and allows to compare them to the ideal results (Fig. 3) [3]. In the current paper, the DE Index is extended to include an evaluation of the safety and lifespan (Fig. 4).

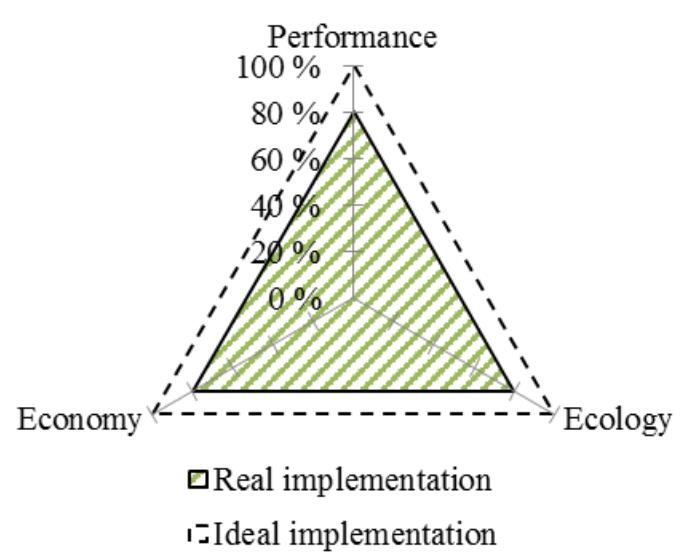

Fig. 3. The old DE model pattern

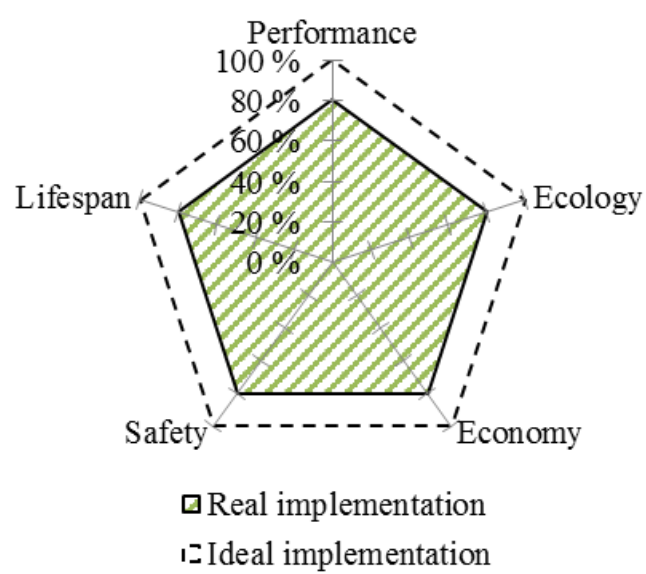

Fig. 4. The new DE model pattern

The evaluation of safety was added to the DE model, because it includes many essential aspects of the technology such as the safety for human health, the protection of the natural resources and the reliability of the technology and for the new technologies, minimizing the risks has become a necessity. On the other hand, the importance of adding the evaluation of the lifespan lies in the fact that this parameter may directly or indirectly affect the other parameters and its impact may not be measured with short-term evaluations. Also, today, there is a need to develop sustainable products, therefore, it is necessary to estimate and improve the lifespan expectancy of the products since the design phase.

\section{APPLICATION OF THE NEW DOUBLE-ECO MODEL TO THE GREASE LUBRICATION CASE OF STUDY}

The DE model was designed to be applied to different types of technology. In this paragraph, the new DE model is applied to a grease lubrication case of study. Unlike many 
technological devices, the lifespan of the grease lubrication can accurately be measured. Also, the difference between the lifespans of the three compared types of grease lubrication is quite large making thus the impact of this parameter clearly identifiable. To apply the DE model, the ecological impact, performances, cost, safety, and lifespan are first separately evaluated then, gathered and compared to the ideal evaluations.

\subsection{DOUBLE-ROLLER EXPERIMENTAL ARRANGEMENT}

The double-roller arrangement (Fig. 5), used in the experimental case of this study, is designed to collect, distribute and adjust the thickness of the grease throughout a machine tool slides. It consists of two outer rollers used to hold the grease and two inner rollers used to control and adjust the grease thickness on the guideways surface. The arrangement also contains bolts and springs used to adjust the load [8], the specifications of the arrangement are presented in Table 1. As lubricant for this experiment, the Miltonic (Nippon Oil Corporation) is used with the Polyisobutylene (PIB).
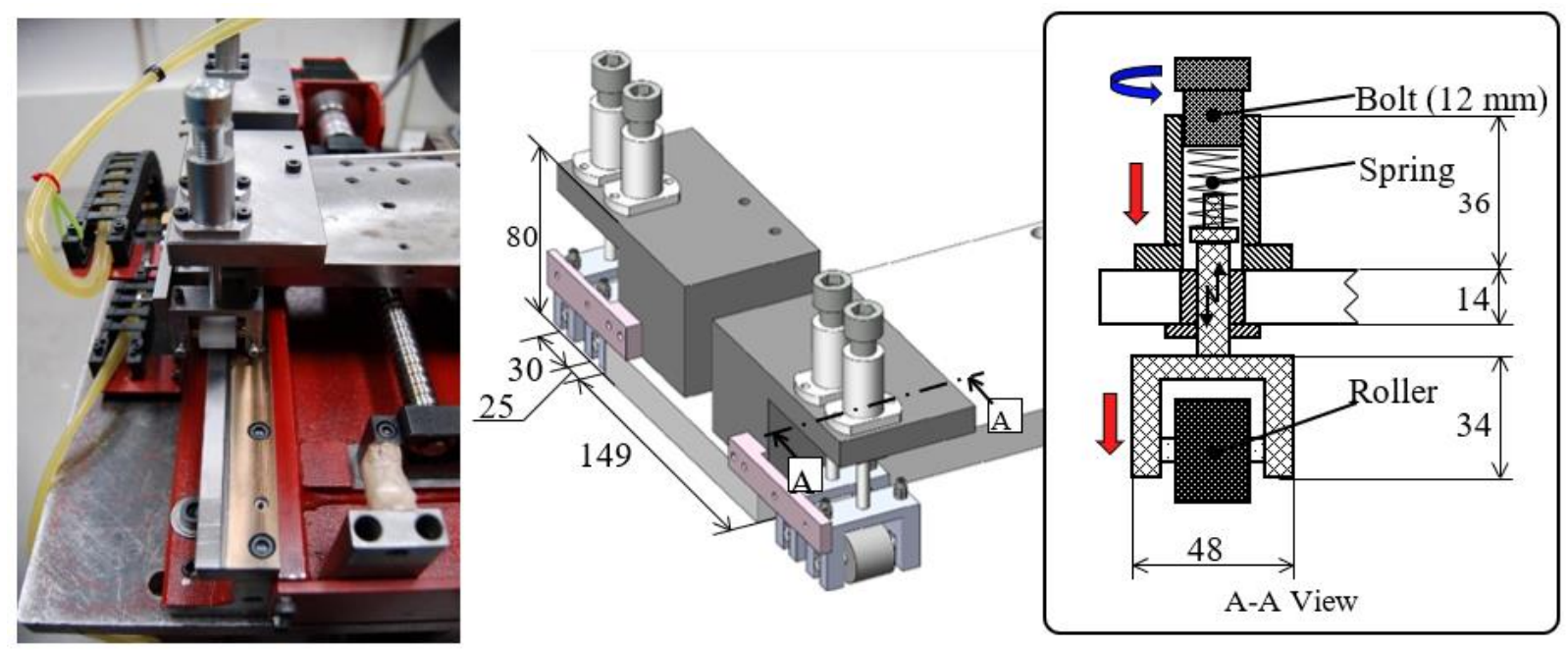

Fig. 5. Double-roller arrangement for the machine tool lubricant distribution

Table 1. Double-roller arrangement specifications

\begin{tabular}{|c|c|c|c|c|c|}
\hline \multicolumn{2}{|c|}{ Transfer Machine } & \multicolumn{2}{|c|}{ Control factors } & $\begin{array}{l}\text { Rollers under the } \\
\text { Best conditions }\end{array}$ & $\begin{array}{l}\text { Rollers under the } \\
\text { Worst conditions }\end{array}$ \\
\hline Feed & $1000 \mathrm{~mm} / \mathrm{min}$ & \multirow{3}{*}{$\begin{array}{l}\text { Outside } \\
\text { roller }\end{array}$} & Material & Felt & Polyurethane \\
\hline Guideway length & $360 \mathrm{~mm}$ & & Diameter & $\Phi 20 \mathrm{~mm}$ & $\Phi 25 \mathrm{~mm}$ \\
\hline Guideway width & $10 \mathrm{~mm}$ & & Load & $2.5 \mathrm{~N}$ & $0.0 \mathrm{~N}$ \\
\hline Table weight & $6.8 \mathrm{~kg}$ & \multirow{3}{*}{$\begin{array}{l}\text { Inside } \\
\text { roller }\end{array}$} & Material & Polyacetal & Felt \\
\hline Dimensions & $360 \times 740 \times 130 \mathrm{~mm}$ & & Diameter & $\Phi 20 \mathrm{~mm}$ & $\Phi 25 \mathrm{~mm}$ \\
\hline Power & $1.2 \mathrm{~kW}$ & & Load & $14.5 \mathrm{~N}$ & $2.5 \mathrm{~N}$ \\
\hline
\end{tabular}

The double-roller arrangement is tested under two different conditions classified in a previous study, based on Taguchi method, as best and worst conditions [8]. Also, the conventional lubrication experiment is conducted and used as a reference. The acceptable 
thickness of the grease lasts $10 \mathrm{~h}$ for the conventional lubrication, $80 \mathrm{~h}$ for the rollers under the worst conditions and $1948 \mathrm{~h}$ under the best conditions. The evolution of the grease thickness during the experiments is presented in the Fig. 6.

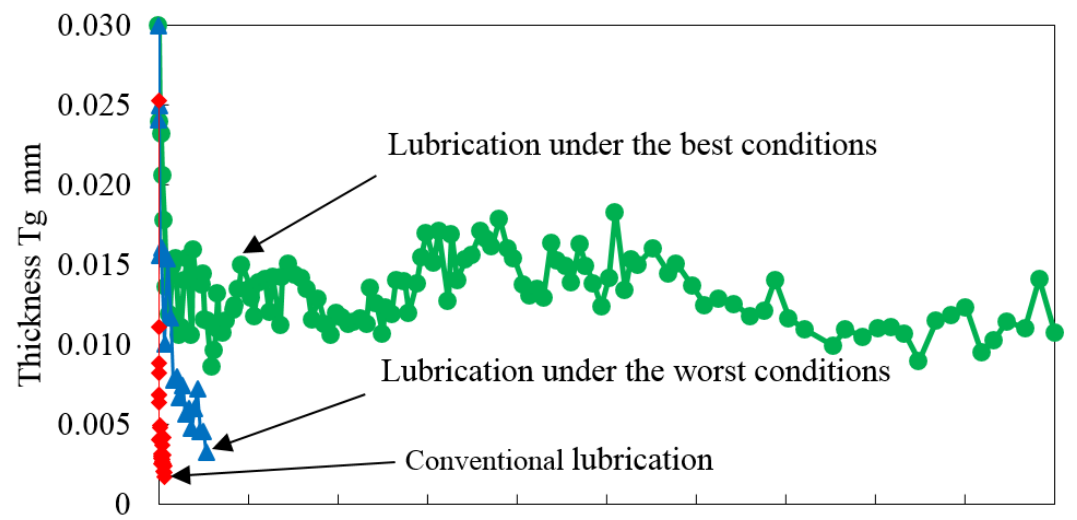

Fig. 6. Grease thickness variation throughout time under different lubrication methods

\subsection{ECOLOGY EVALUATION}

This evaluation is carried out based on the Life Cycle Assessment (LCA), an approach used to measure the environmental impacts of a product during its life cycle from the materials extraction to the manufacturing, use, and end-of-life. Salling [9] introduced an evaluation approach that relies on weighting based on polling, surveys and economic studies in order to define the importance of the environmental parameters. Similarly, Bevilacqua explained the importance of weighting as a form of normalization to define the environmental categories [10]. Based on that, ten DE categories for the environmental analysis are introduced and scored in a scale from 1 to 10,1 being the lowest performance, 10 the highest one and 0 is assigned when there is no performance (Table 2).

Table 2. Scores assigned to the environment categories in the grease lubrication case

\begin{tabular}{|l|c|c|c|c|}
\hline \multicolumn{1}{|c|}{ DE Category } & Units & $\begin{array}{c}\text { Roller (Best } \\
\text { Conditions) }\end{array}$ & $\begin{array}{c}\text { Rollers (Worst } \\
\text { Conditions) }\end{array}$ & $\begin{array}{c}\text { Conventional } \\
\text { Lubrication }\end{array}$ \\
\hline 1. Locality (local-to-local approach) & $(\mathrm{km})$ & 10 & 10 & 10 \\
\hline 2. Renewability & yes/no/partially & 5 & 5 & 5 \\
\hline $\begin{array}{l}\text { 3. Durability (frequency of mainte- } \\
\text { nance or repair) }\end{array}$ & (times/year) & 10 & 8.9 & 0 \\
\hline 4. Energy efficiency & yes/no/partially & 10 & 10 & 10 \\
\hline 5. Emissions minimization $\mathrm{CO}_{2}$ & (kg/year) & 10 & 8.7 & 0 \\
\hline 6. Noise / Vibrations & yes/no/partially & 10 & 10 & 10 \\
\hline 7. Waste minimization & TMR (kg/year) & 10 & 8.7 & 0 \\
\hline $\begin{array}{l}\text { 8. By-product safety (Absence of } \\
\text { side effects) }\end{array}$ & yes/no/partially & 10 & 10 & 10 \\
\hline 9. Recyclability & yes/no/partially & 5 & 5 & 5 \\
\hline $\begin{array}{l}\text { 10. End-of-life waste bioremedia- } \\
\text { tion (products that can be } \\
\text { reprocessed into their nature) }\end{array}$ & yes/no/partially & 5 & 5 & 5 \\
\hline \multicolumn{2}{|c|}{ Total } & 85 & 81.3 & 55 \\
\hline
\end{tabular}


In the scoring, the following considerations are taken:

- The emission's calculation is made using a coefficient developed by the Japanese ministry of environment $[8,11](0.01 \mathrm{~g}$ under the best conditions, $0.27 \mathrm{~g}$ under the worst conditions and $1.81 \mathrm{~g}$ for the conventional lubrication).

- The waste minimization consists on considering the annual amount of used grease $(0.38 \mathrm{~g}$ under the best conditions, $7.10 \mathrm{~g}$ under the worst conditions and $47.30 \mathrm{~g}$ for the conventional lubrication).

- The grease can be re-refined, repurposed or properly disposed [12]. The reason why the score 5 is assigned to the categories recyclability, renewability and end-of-life waste bioremediation.

\subsection{MECHANICAL PERFORMANCES EVALUATION}

The performances evaluation is carried out using the Mahalanobis Taguchi System (MTS), a method that allows to analyse and evaluate multivariate data of a technology $[13,14]$. The MTS requires the definition of a Mahalanobis Distance (MD), also called Unit Group, which measures the mean values of a certain data population that constitutes the Mahalanobis Space (MS). The application of the MTS to evaluate the performances of grease lubrication is made using a software with two steps analysis; first, creating an appropriate MS then, validating the reference space through abnormal data measurements. Three parameters are selected; $T g_{2 \mathrm{~h}}$, the lubrication thickness after 2 hours of the initial run, $T_{5 \mu \mathrm{m}}$, the time when the grease thickness reaches the thresholds $5 \mu \mathrm{m}$ and $\Delta T g$, the grease thickness variation. The conventional lubrication evaluations are used to define the MS and the results of the rollers are considered as abnormal data (Table 3). Here, it is possible to demonstrate a confirmation run with abnormal conditions using the largest MD values and create a ranking.

Table 3. The mechanical performances evaluation in the grease lubrication case using the MTS

\begin{tabular}{|l|c|c|c|c|}
\hline \multicolumn{9}{|c|}{ Input data } & $\begin{array}{c}\text { Output data } \\
\text { Confirmation run (MD) }\end{array}$ \\
\hline Variables & $\begin{array}{c}\text { Thickness } T g_{2 h} \\
\text { after 2 hrs }[\mu \mathrm{m}]\end{array}$ & $\begin{array}{c}\text { Time } T_{5 \mu \mathrm{m}} \text { at } 5 \mu \mathrm{m} \\
\text { thickness }[\mathrm{h}]\end{array}$ & $\begin{array}{c}\Delta T_{g} \\
{[\mu \mathrm{m} / \mathrm{h}]}\end{array}$ & Largest MD Values \\
\hline \multicolumn{7}{|c|}{ Conditions used to create the MS } \\
\hline $\begin{array}{l}\text { Conventional } \\
\text { Lubrication }\end{array}$ & 4.95 & 1 & -2.290 & 0.001 \\
\hline \multicolumn{7}{|c|}{ Abnormal conditions to validate the MS } \\
\hline $\begin{array}{l}\text { Rollers (Best } \\
\text { Conditions) }\end{array}$ & 23.92 & 1948 & -0.013 & 19.642 \\
\hline $\begin{array}{l}\text { Rollers (Worst } \\
\text { Conditions) }\end{array}$ & 15.58 & 55 & -0.334 & 0.534 \\
\hline
\end{tabular}

\subsection{ECONOMY EVALUATION}

Several considerations are made for the economy evaluation of the case of grease lubrication. The production and usage costs are calculated over 2920 hours of operation, the equivalent of 365 days with one shift working 8 hours a day. The research and 
development costs and the disposal costs are thus omitted. The electricity fees are taken equal to $0.15 \mathrm{USD} / \mathrm{kWh}$, the highest electricity rate according to the Japanese Government [15] and the labour hourly wage is taken equal to 23.6 USD [16]. Besides, the assembly duration is about 5 hours, the monitoring takes 5 minutes per day and the grease disposal lasts 10 minutes. The assembly and utilities costs are included in the procurement costs. The consumable costs are estimated based on a 97\% Multinoc grease and 3\% Polyisobutylene mixture. The results show that the roller arrangement used under the best conditions is $18.17 \%$ cheaper than the conventional lubrication (Table 4).

Table 4. The total annual cost evaluation in the case of grease lubrication

\begin{tabular}{|l|c|c|c|}
\hline \multicolumn{1}{|c|}{ Cost categories } & $\begin{array}{c}\text { Rollers } \\
\text { (Best Conditions) }\end{array}$ & $\begin{array}{c}\text { Rollers } \\
\text { (Worst Conditions) }\end{array}$ & $\begin{array}{c}\text { Conventional } \\
\text { Lubrication }\end{array}$ \\
\hline Procurement & 433.90 USD & 469.91 USD & 0 USD \\
\hline Manufacturing and setup & 118.00 USD & 118.00 USD & 0 USD \\
\hline Operation & 7.66 USD & 143.57 USD & 1148.53 USD \\
\hline Utilities & 1621.81 USD & 1621.81 USD & 1621.81 USD \\
\hline Consumables & 0.003 USD & 0.060 USD & 0.403 USD \\
\hline Maintenance & 472.00 USD & 472.00 USD & 472.00 USD \\
\hline Total Cost & 2653.37 USD & 2825.35 USD & 3242.74 USD \\
\hline
\end{tabular}

\subsection{SAFTY EVALUATION}

The risk is defined as the severity of the consequences of an activity with respect to something that humans value [17]. It may thus hinder the technology's performances and have an impact on both humans and the environment. Therefore, the safety is an important characteristic to be evaluated for any type of technology. In this section, three categories of risks are considered: risks on human health, risks on the environment and business associated risks [18-22].

Table 5. Scores assigned to the risk categories in the grease lubrication case

\begin{tabular}{|c|c|c|c|c|}
\hline Risks classifications & Risks Category & $\begin{array}{c}\text { Roller } \\
\text { (Best conditions) }\end{array}$ & $\begin{array}{c}\text { Rollers } \\
\text { (Worst conditions) }\end{array}$ & $\begin{array}{c}\text { Conventional } \\
\text { lubrication }\end{array}$ \\
\hline \multirow{6}{*}{ Human Health Risks } & 1. Acute oral toxicity & 10 & 5 & 1 \\
\hline & 2. Acute dermal toxicity & 10 & 5 & 1 \\
\hline & 3. Acid burns & 10 & 5 & 1 \\
\hline & 4. Skin effects & 10 & 5 & 1 \\
\hline & 5. Respiratory effects & 10 & 5 & 1 \\
\hline & 6. Internal effects & 10 & 5 & 1 \\
\hline Environmental Risks & $\begin{array}{l}\text { 7. Greenhouse Gas } \\
\text { Potential }\end{array}$ & 10 & 5 & 1 \\
\hline \multirow{3}{*}{ Business Risks } & 8. Resource scarcity & 5 & 5 & 1 \\
\hline & 9. Price escalation & 5 & 5 & 1 \\
\hline & 10. Trust & 10 & 5 & 1 \\
\hline \multicolumn{2}{|c|}{ Total } & 90 & 50 & 10 \\
\hline
\end{tabular}

The estimation of the risks threatening the human health and the environment due to lubricant use and pollutants generation is calculated based on the green gas emission. To do this, the quantity of used grease for the three types of lubrication is measured then, 
the equivalent of $\mathrm{CO}_{2}$ greenhouse gas potential is calculated using a coefficient of grease obtained from Mantoam's study [23]. The results show that the carbon emission is equivalent to $0.002 \mathrm{CO}_{2}$-eq g/year for the rollers under the best conditions, $0.037 \mathrm{CO}_{2}$-eq $\mathrm{g} / \mathrm{year}$ under the worst conditions and $0.251 \mathrm{CO}_{2}$-eq g/year for the conventional lubrication. The other risk categories are subjectively weighted based on literature reviews. The high potential risk categories are scored with 1 and the less potential with 10 (Table 5).

\subsection{LIFESPAN EVALUATION}

Extending the lifespan of a technology was proven to be an environmentally-friendly approach, however, an old technology is usually linked to low performances, additional maintenance and reparation costs, low profit for the manufacturer, high risks, etc. The methods of estimating the lifespan expectancy and evaluating the impacts of extending the lifespan of a technology depend on the technology itself and the environment of its use (e.g. frequency, load, environmental conditions and user). It usually includes multivariate parameters. Thus, it is appropriate to use the MTS. Here, it is worthwhile mentioning that in some cases, the lifespan can affect positively or negatively some aspects of the technology but not the target performances. Hence, the aspects to be taken into account should be carefully selected based on the targeted performances. For the case of grease lubrication, the cost and safety evaluations were made along one year, a period longer than the lifespans of the three studied cases. Therefore, the evaluations are valid for the long-term and the long lifespan does not affect them. The evaluation of the lifespan and its impacts on the mechanical performances is presented in Table 6. Three selected parameters are evaluated; the lifespan, $\mathrm{Tg}_{\text {average }}$ the average thickness of lubricant layer and $\operatorname{Cov}(\mathrm{Tg})$, the covariance of the grease thickness. Then, the Recognition Taguchi (RT) method is used to rate the three cases of lubrication. The worst results for every selected parameter are used to define the MS and the results of the evaluations under the three conditions are considered as abnormal data.

Table 6. The lifespan evaluation in the grease lubrication case using the MTS

\begin{tabular}{|c|c|c|c|c|}
\hline \multicolumn{4}{|c|}{ Input data } & \multirow{2}{*}{$\begin{array}{c}\text { Output data } \\
\text { Confirmation run (MD) } \\
\text { Largest MD Values } \\
\end{array}$} \\
\hline Variables & Lifespan [h] & $\operatorname{Tg}_{\text {Average }}[\mu \mathrm{m}]$ & $\operatorname{Cov}(T g)$ & \\
\hline \multicolumn{5}{|c|}{ Conditions used to create the MS } \\
\hline Worst evaluations & 10 & 13.094 & 3.837 & 0.00 \\
\hline \multicolumn{5}{|c|}{ Abnormal conditions to validate the MS } \\
\hline $\begin{array}{l}\text { Conventional } \\
\text { Lubrication }\end{array}$ & 10 & 5.196 & 2.217 & 0.01 \\
\hline $\begin{array}{l}\text { Rollers (Best } \\
\text { Conditions) }\end{array}$ & 1948 & 13.094 & 2.424 & 4.05 \\
\hline $\begin{array}{l}\text { Rollers (Worst } \\
\text { Conditions) }\end{array}$ & 80 & 9.126 & 3.837 & 0.15 \\
\hline
\end{tabular}

The rollers under the best conditions have a higher evaluation than the conventional lubrication and the rollers at the worst conditions. Thus, it can be assumed that for the current case of study, the long lifespan adds a value to the technology and does not affect negatively any of its aspects. 


\subsection{COMPARISON OF DE TECHNOLOGIES EFFICIENCIES}

In this section, for each studied case of grease lubrication, the previous evaluations are compared to the ideal evaluations through the DE model. The standardization of all the evaluations is made by assigning a score from 10 to 100 to every evaluation. In the case of evaluations made with concrete measured values, 100 is assigned to the best result, 10 to the worst one and the third value is deduced through a linear calculation (Table 7).

Table 7. Index of the long life technology model efficiency for each technology for machine tool lubrication

\begin{tabular}{|l|c|c|c|c|c|c|c|}
\hline \multicolumn{1}{|c|}{ Technology } & Performances & Economy & Ecology & Safety & Lifespan & $\begin{array}{c}\text { Calculated } \\
\text { area }\left(\mathrm{u}^{2}\right)\end{array}$ & $\begin{array}{c}\text { DE Index } \\
(\%)\end{array}$ \\
\hline $\begin{array}{l}\text { DE Ideal } \\
\text { Implementation }\end{array}$ & 100 & 100 & 100 & 100 & 100 & 24826.1 & 100 \\
\hline $\begin{array}{l}\text { Conventional } \\
\text { lubrication }\end{array}$ & 10 & 10 & 55 & 10 & 10 & 695.13 & 2.80 \\
\hline $\begin{array}{l}\text { Roller Best } \\
\text { condition }\end{array}$ & 100 & 100 & 85 & 90 & 100 & 22417.96 & 90.30 \\
\hline $\begin{array}{l}\text { Roller worst } \\
\text { condition }\end{array}$ & 12.7 & 76 & 81.3 & 50 & 13.12 & 5973.965 & 24.06 \\
\hline
\end{tabular}

The comparison of the implementations of the studied cases with the ideal implementation (Fig 7) shows that the double rollers arrangement used under the best conditions has the highest performances in the portfolio; it covers $90.3 \%$ of the ideal implementation's area while the conventional lubrication covers only $2.8 \%$ and the rollers under the worst conditions convers $24.06 \%$ of the same area. Table 8 summarizes the evaluations of the studied cases of grease lubrication based on the DE index with three, four and five parameters. For the same experimental data, the evaluation of the system is different when considering more parameters in the DE index. This means that for the evaluations with three and four parameters, some factors impacting the system were neglected. In addition, for the current experimental case, the evaluation with three different DE led to the same ranking of the compared lubrications, however, for a different technology, depending on the lifespan impact, the ranking may change when adding the lifespan to the evaluated parameters. Therefore, it is important to add an evaluation of the lifespan and to carefully select the aspects it may impact.

Table 8. Comparison of the evaluations of the grease lubrication case based on the DE with different parameters

\begin{tabular}{|l|c|c|c|}
\hline \multirow{2}{*}{ Technology } & \multicolumn{3}{|c|}{ DE index parameters } \\
\cline { 2 - 4 } & $\begin{array}{c}\text { Performances, Ecology, } \\
\text { Economy }\end{array}$ & $\begin{array}{c}\text { Performances, Ecology, } \\
\text { Economy, Safety }\end{array}$ & $\begin{array}{c}\text { Performances, Ecology, } \\
\text { Economy, Safety, } \\
\text { Lifespan }\end{array}$ \\
\hline $\begin{array}{l}\text { Conventional } \\
\text { lubrication }\end{array}$ & $4 \%$ & $3.25 \%$ & $2.8 \%$ \\
\hline $\begin{array}{l}\text { Rollers under the } \\
\text { worst conditions }\end{array}$ & $26.4 \%$ & $28.3 \%$ & $24.06 \%$ \\
\hline $\begin{array}{l}\text { Rollers under the best } \\
\text { conditions }\end{array}$ & $90 \%$ & $87.5 \%$ & $90.3 \%$ \\
\hline
\end{tabular}



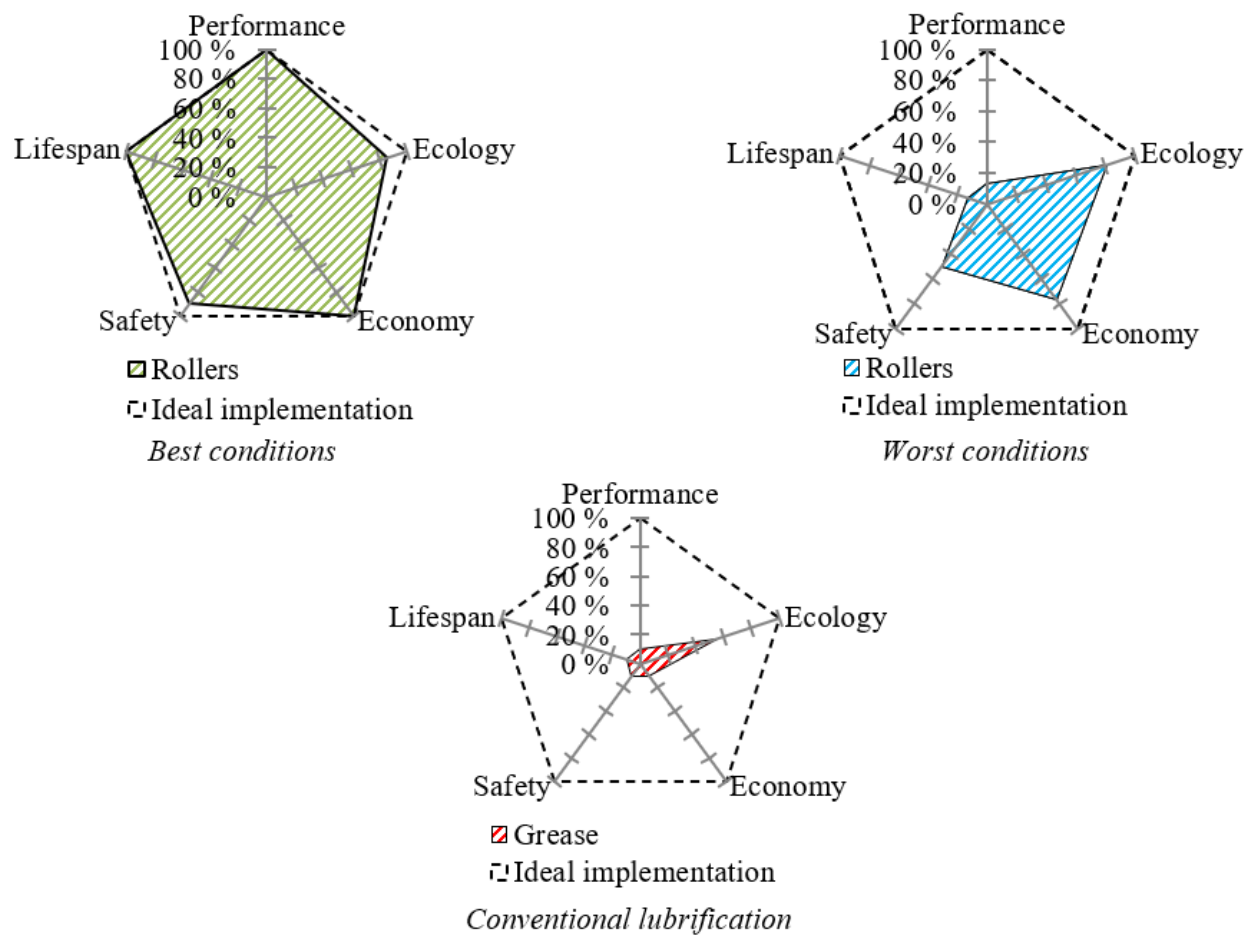

Fig. 7. Results of the new DE evaluation for each technology in the experimental case

\section{CONCLUSION}

This article was designed to study the approach of extending the lifespan of technologies and introduce an evaluation platform including the lifespan. First, the aspects and challenges of extending the lifespan were studied through the example of PCs. Then the DE model, an evaluation's platform introduced in a previous study, was extended to include an evaluation of the safety and lifespan in addition to the performances, cost and environmental impact evaluations. As case of study, the DE was applied to three types of grease lubrication; the conventional lubrication, the rollers used under the best conditions (also called permanent grease lubrication) and the rollers used under the worst conditions. The results showed that (1) adding the safety and lifespan parameters to the DE model made it more efficient in the evaluation of technologies (2) based on the DE evaluation, the permanent grease lubrication, having the longest lifespan (1948 h), has a better evaluation then the rollers used under the worst conditions $(80 \mathrm{~h})$ and the conventional lubrication $(10 \mathrm{~h})$. In fact, it reaches $90.3 \%$ of the ideal characteristics while the rollers technology used under the worst conditions reaches $24.06 \%$ and the conventional lubrication $2.8 \%$.

\section{REFERENCES}

[1] COOPER T., 2005, Slower Consumption: Reflections on Product Life Spans and the Throwaway Society, Journal of Industrial Ecology, 9/1-2, 51-67.

[2] OSIBANJO O., NNOROM I.C., 2007, The Challenge of Electronic Waste (e-Waste) Management in Developing Countries, Waste Management Research, 25/6, 489-501. 
[3] PENA-GONZALEZ E., DA SILVA P., TANABE I., 2018, Development of Environmentally-Friendly Technologies Based on the Double-Eco Model-An Evaluation Platform, Journal of Machine Engineering, 18/1, 18-31.

[4] WILlIAMS E., HATANAKA T., 2005, Residential Computer Usage Patterns in Japan and Associated Life Cycle Energy Use, Proceedings of the 2005 IEEE International Symposium on Electronics and the Environment, 177-182.

[5] YOSHIDA A., TASAKI T., TERAZONO A., 2009, Material Flow Analysis of Used Personal Computers in Japan, Waste Management, 29/5, 1602-1614.

[6] WILLIAMS E., 2004, Energy Intensity of Computer Manufacturing: Hybrid Assessment Combining Process and Economic Input- Output Methods, Environmental Science \& Technology, 38/22, 6166-6174.

[7] LeBel S., 2016, Fast Machines, Slow Violence: ICTs, Planned Obsolescence, and e-Waste, Globalizations, 13/3, 300-309.

[8] TANABE I., WATANABE M., 2011, Development of Cost-Effective and Eco-Friendly Permanent Grease Lubrication for the Machine Tool Slides, 2011 IEEE International Symposium on Assembly and Manufacturing (ISAM).

[9] SALLING P., KICHERER A., DITTRICH-KRÄMER B., et al., 2002, Eco-Efficiency Analysis by BASF: The Method, The International Journal of Life Cycle Assessment, 7/4, 203-218.

[10] BEVIlACQUA M., CIARAPICA F., GIACCHETTA G., 2012, Design for Environment as a Tool for the Development of Sustainable Supply Chain, Springer-Verlag London, Ltd., UK.

[11] TANABE I., 2016, Double-ECO Model Technologies for and Environmentally-Friendly Manufacturing, Procedia CIRP: 23rd CIRP Conference on Life Cycle Engineering, 48, 495-501.

[12] DIPHARE M., PILUSA J., 2013, A Review of Waste Lubricating Grease Management, 2nd International Conference on Environment, Agriculture and Food Sciences, 131-134.

[13] TAGUCHI G., JUGULUM R., 2002, The Mahalanobis-Taguchi Strategy: A Pattern Technology System, SpringerVerlag London, Ltd., United Kingdom.

[14] CUDNEY E., HONG J., JUGULUM R., 2007, An Evaluation of Mahalanobis-Taguchi System and Neural Network for Multivariate Pattern Recognition, JISE, 1/2, 139-150.

[15] Japanese ministry of economy, trade and industry, 2016, Japan's energy: 20 Questions to understand the current energy situation, http://www.enecho.meti.go.jp/en/category /brochures/pdf/japan_energy_2016.pdf.

[16] LEVINSON M., 2017, U.S. Manufacturing in International Perspective, Congressional Research Service, United States.

[17] AVEN T., 2016, Risk Assessment and Risk Management: Review of Recent Advances on Their Foundation, European Journal of Operational Research, 253, 1-13.

[18] DA SILVA P., TANABE I., 2018, The Analysis of Environmental and Human Impacts of Using Strong Alkaline Water for Cooling During Machining, Journal of Machine Engineering, 18/1, 32-44.

[19] SCHWARZ M., DADO M., HNILICA R., VEVERKOVA D., 2015, Environmental and Health Aspects of Metalworking Fluid Use, Polish Journal of Environmental Studies, 24/1, 37-45.

[20] MADAHIRE I., MBOHWA C., 2016, Lubricant Additive Impacts on Human Health and the Environment, Springer International Publishing, Switzerland.

[21] MIRER F.E., 2010, New Evidence on the Health Hazards and Control of Metalworking Fluids Since Completion of the OSHA Advisory Committee Report, AJIM, 53, 792-801.

[22] McKONE, T.E., HERTWICH E.G., 2001, The Human Toxicity Potential and a Strategy for Evaluating Model Performance in Life Cycle Impact Assessment, International Journal of Life-Cycle Assessment, 6/2, 106-109.

[23] MANTOAM E.J., ROMANELLI T.L, GIMENEZ L.M. AND MILAN M., 2017, Energy Demand and Greenhouse Gases Emissions in the Life Cycle of Coffee Harvesters, Chemical Engineering Transactions, 58, 175-180. 